\title{
Information Flow And Trading Dynamics: A Theoretical Approach
}

Megan Y. Sun, University of Wisconsin - River Falls, USA

\begin{abstract}
This paper constructs a theoretical mixture of distributions model to describe the impacts of permanent fundamental, transitory fundamental, and non-fundamental shocks on returns, volatility and volume. Under the assumption that informed traders share homogenous fundamental information, we find that only contemporaneous noise trading contributes to the generation of trading volume. This theoretical model provides us with three identifying restrictions that can be readily imposed on a trivariate SVAR model to empirically estimate the impacts of the three shocks on returns, volatility, and volume. Using this model, we find that Microsoft stock prices are not very sensitive to noise trading.
\end{abstract}

Keywords: permanent shocks; transitory shocks; non-fundamental shocks; trading volume; returns; volatility

\section{INTRODUCTION}

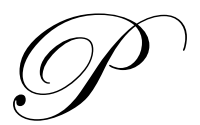

rior literature shows that investors trade in response to both fundamental and non-fundamental shocks [e.g. Wang (1994), He and Wang (1995), Campbell, Grossman, and Wang (1993), Lee and Rui (2001), and Sun (2008)]. Any shock that induces price changes by affecting earnings, dividends or discount factors, directly or indirectly, is fundamental; any shock that influences stock prices without affecting the dividend discounting process is non-fundamental. Following Lee (1998), fundamental shocks can be further decomposed into permanent fundamental and transitory fundamental shocks. Permanent fundamental shocks involve permanent changes in earnings, dividends, or discount factors in the stock valuation process. Transitory fundamental shocks entail temporary changes in the above factors, therefore, their long-run cumulative effects on earnings, dividends, and discount factors, and hence on returns are zero, distinguish them from permanent ones. These three types of shocks - permanent fundamental, transitory fundamental, and non-fundamental - combine to constitute information.

When information arrives at the market, as De Long et al. (1990) note, investors do not respond to the information homogenously. Some investors are informed traders and others are noise traders ${ }^{1}$. Informed traders can distinguish between fundamental and non-fundamental shocks, hence they respond only to fundamental shocks and develop rational expectations accordingly. They buy when their information indicates that the stock is undervalued and sell when their information indicates that the stock is overvalued. Their trading pushes prices towards the direction of fundamental values. Noise traders, on the other hand, cannot single out fundamental shocks from nonfundamental ones, therefore, they respond to both types of shocks. They irrationally and falsely believe that nonfundamental shocks carry true information that affects the fundamental value of the stock and make buy or sell decisions based on their incorrect beliefs. In essence, fundamental shocks, including both permanent and transitory ones, will cause both informed traders and noise traders to change their valuation of the stock, while nonfundamental shocks will only affect noise traders' valuation of the stock.

Therefore, when information arrives at the market, it comes in a combination of permanent fundamental, transitory fundamental, and non-fundamental shocks. Informed traders respond only to fundamental shocks, while noise traders respond to all three types of shocks, including non-fundamental ones. Their responses to the information flow process generate returns, volatility, and volume. One of the major topics in finance is how the three shocks contribute to the movement and co-movement of returns, volatility, and volume, a subject into which prior literature has not delved comprehensively. This paper fills this void in the literature. 
By using a framework similar to that in Tauchen and Pitts (1983), we propose a trivariate mixture of distributions model to explain how permanent fundamental, transitory fundamental, and non-fundamental shocks contribute to the generation of returns, volatility, and volume. Under the assumption of homogenous informed traders and heterogeneous noise traders, we confirm the conclusion of Campbell, Grossman, and Wang (1993), Lee and Rui (2001) and Sun (2008) that only non-fundamental shocks initially affect trading volume, although fundamental shocks, both permanent and transitory, could have lagged effects on trading volume. This theoretical model provides us with three identifying restrictions that can be applied to a trivariate SVAR model of returns, volatility, and volume ${ }^{2}$. By applying the model to Microsoft stock prices, we find that Microsoft stock returns are not sensitive to noise trading at all. Returns are mainly driven by permanent fundamental shocks, volatility is primarily affected by transitory fundamental shocks, while volume is mostly driven by non-fundamental shocks.

The remainder of this paper is organized as follows. In the next section (section 2), we discuss related prior literature. In section 3, we outline the theoretical model. In section 4, we provide an empirical application of the model. In section 5, we conclude the paper with a summary of the evidence.

\section{PREVIOUS RESEARCH}

Clark (1973) and Epps and Epps (1976), followed by Tauchen and Pitts (1983), suggest that joint distribution of price changes (return) and trading volume are driven by an unobserved mixing variable that may be loosely interpreted as an information arrival process, which inspires the application of a mixture of distributions model to the dynamic relationship of price change and volume. To date, quite a few research papers have tried to determine how to proxy or even model the information flow process.

For example, Harris (1987) shows that the number of transactions for individual stocks can be a good proxy for the speed of the information arrival process. Lamoureux and Lastrapes (1990) believe trading volume itself could be a good proxy for the information flow process. Recently, statistical models have been introduced to model the information flow process. For instance, Foster and Viswanathan (1993) find that the lognormal distribution of information flow best suits the intertemporal trading model of stock prices and volume in the context of a mixture of distributions model. Richardson and Smith (1994) also show that the lognormal distribution of information flows is favored more by the mixture of distributions model than by a standard normal distribution. Lamoureux and Lastrapes (1994) argue that the information arrival process assumed by previous studies cannot generate the shortrun dependence in both trading volume and volatility when using a mixture model with one latent common factor restricting the joint density of returns and volume. Later, Anderson (1996) presents a modified mixture of distributions model, where information flow, serving as a latent variable, is modeled as a stochastic volatility process. Mahieu and Bauer (1998) extend Anderson's (1996) modified mixture model by using the Markov chain Monte Carlo (MCMC) simulation to study the latent information process. At the same time, Liesenfeld (1998) uses the mixture model to relate price change to volume, with an unobserved number of price-relevant information flows serving as a common mixing variable. Watanabe (2000) employs a bivariate mixture model using a Bayesian method via the MCMC technique serving as a latent variable for the information. Liesenfeld (2001) expands on his earlier work [Liesenfeld (1998)] by adding another latent variable, trader's sensitivity to new information, to the mixture model and thus generalizes his original model. In the resulting generalized mixture model, the behavior of price change and trading volume results from the simultaneous interaction of the number of information arrivals and traders' sensitivity to new information. Fleming, Kirby, and Ostdiek (2006) use state-space methods for the latent information process to investigate the relation between volume, volatility, and $\mathrm{ARCH}$ effects within a mixture of distributions hypothesis framework.

As seen from above, the mixture of distributions model has been widely used in prior literature to explain the dynamic relationship between returns and volume ${ }^{3}$. The information flow process, proxied by number of transactions, trading volume, a lognormal distribution, a stochastic volatility process, or a MCMC, serves as a mixing variable in the various mixture of distributions models. Prior literature agrees that if properly designed, a mixture model can help resolve some important issues in finance.

However, none of the above papers consider volatility explicitly in their mixture of distributions models. Furthermore, all of the above papers treat information flow as a single process and fail to recognize that the 
information is a mixture of three shock components (permanent fundamental, transitory fundamental, and nonfundamental shocks) and that investors respond differently to these three types of shocks. We therefore propose in this paper that by decomposing information flow into permanent fundamental, transitory fundamental, and nonfundamental shocks we could shed more light on how returns, volatility, and volume are simultaneously affected by information flow.

\section{THEORETICAL MODEL}

Let us suppose that two types of traders are in the market: informed traders and noise traders. Several assumptions about informed traders and noise traders need to be postulated before the actual model is formulated. First, informed traders have the ability to single out fundamental shocks from non-fundamental shocks. They reach correct conclusions on the valuation of the stock based on fundamental information concerning earnings, dividend, or discount factors. Informed traders respond only to fundamental shocks, including both permanent and transitory fundamental shocks. Second, noise traders cannot distinguish fundamental shocks from non-fundamental. shocks. Hence noise traders respond to both non-fundamental and fundamental shocks. Noise traders irrationally and falsely believe that these non-fundamental shocks affect the fundamental value of the stock, though non-fundamental shocks do not have the ability to affect fundamental values of the stock. It is noise traders' susceptibility to nonfundamental shocks that distinguishes noise traders' responses from those of informed traders. Third, we assume in this model that informed traders are homogenous as in De Long et al. (1990), but noise traders are heterogeneous. According to Kelly (1997), investors have different degrees of sensitivity to noise (non-fundamental shocks). As a result, one noise trader may conclude differently from another noise trader about the "fundamental" value of the market, hence noise traders are heterogeneous.

We further assume that the market consists of $\mathrm{J}$ informed traders and $\mathrm{N}$ noise traders and that these traders take either long or short positions in an asset ${ }^{4}$. Throughout a given day the market passes through a sequence of equilibriums. It is the arrival of information to the market that initiates the movement from the $(i-1)$ th to the $i$ th within-day equilibrium,

At the time of the $i$ th within-day equilibrium the desired position $Q_{i j}$ of the jth informed trader is given by

$$
Q_{i j}=a\left[P_{i j}^{*}-P_{i}\right]
$$

Where a $>0$ is a constant, representing the coefficient of absolute risk aversion, $P_{i j}^{*}$ is the $j$ th informed traders' reservation price, and $P_{i}$ is the current market price. Note that informed trader's reservation price, $P_{i j}^{*}$, changes only in response to permanent fundamental and transitory fundamental shocks. Based on the assumption that informed traders interpret both types of fundamental shocks correctly and homogeneously, $P_{i j}^{*}$ does not vary across informed traders, and therefore $P_{i}^{*}$ should be used instead. However, in order to facilitate the following derivation process, the symbol $P_{i j}^{*}$ is still used.

Similarly, the desired position $Q_{i n}$ of the $n$th noise trader is given by

$$
Q_{i n}=a\left[P_{i n}^{*}-P_{i}\right]
$$

where a $>0$ is a constant, representing the coefficient of absolute risk aversion ${ }^{5}, P_{i n}^{*}$ is the $n$th noise trader's reservation price, and $P_{i}$ is the current market price. Note that noise trader's reservation price, $P_{i n}^{*}$, changes in response to permanent and transitory fundamental shocks and non-fundamental shocks as well. Since 
noise traders are heterogeneous, $P_{i n}^{*}$ may vary across these noise traders. For simplicity, we assume that the numbers of informed traders, $\mathrm{J}$, and noise traders, $\mathrm{N}$, are fixed within the day.

Since in equilibrium, total number of buy orders matches the total number of sell orders,

$\sum_{j=1}^{J}\left(Q_{i j}-Q_{(i-1) j}\right)+\sum_{n=1}^{N}\left(Q_{i n}-Q_{(i-1) n}\right)=0$.

This implies the following price change:

$\Delta P_{i}=\frac{1}{J+N}\left(\sum_{j=1}^{J} \Delta P_{i j}^{*}+\sum_{n=1}^{N} \Delta P_{i n}^{*}\right)$

where $\Delta P_{i j}^{*}=P_{i j}^{*}-P_{(i-1) j}^{*}, \Delta P_{i n}^{*}=P_{i n}^{*}-P_{(i-1) n}^{*}$ and $\Delta P_{i}=P_{i}-P_{(i-1)}$

Proof (See Appendix A)

Accordingly, volume is half of the total position change.

$V_{i}=\frac{1}{2} \sum_{j=1}^{J}\left|Q_{i j}-Q_{(i-1) j}\right|+\frac{1}{2} \sum_{n=1}^{N}\left|Q_{i n}-Q_{(i-1) n}\right|$

We can prove that the above equation can be rewritten as

$V_{i}=\frac{a}{2} \sum_{j=1}^{J}\left|\Delta P_{i j}^{*}-\Delta P_{i}\right|+\frac{a}{2} \sum_{n=1}^{N}\left|\Delta P_{i n}^{*}-\Delta P_{i}\right|$

Proof (See Appendix B)

Since price change can be induced by three mutually independent shock components: permanent fundamental, transitory fundamental, and non-fundamental shocks, a variance-components model for price change is specified as follows:

$\Delta P_{i j}^{*}=\phi_{i j}+\psi_{i j}, \quad \Delta P_{i n}^{*}=\phi_{i j}+\psi_{i j}+\eta_{i n}$

$E\left(\phi_{i j}\right)=E\left(\psi_{i j}\right)=E\left(\eta_{i n}\right)=0, \quad \operatorname{var}\left(\phi_{i j}\right) \equiv \sigma_{\phi}^{2}, \quad \operatorname{var}\left(\psi_{i j}\right) \equiv \sigma_{\psi}^{2}, \quad \operatorname{var}\left(\eta_{i n}\right) \equiv \sigma_{\eta}^{2}$

where $\phi_{i j}$ represents permanent fundamental shocks, $\quad \psi_{i j}$ represents transitory fundamental shocks, and $\eta_{i n}$ represents non-fundamental shocks (noise). Since informed traders only respond to permanent and transitory fundamental shocks, informed traders' reservation price change $\Delta P_{i j}^{*}$ is decomposed into permanent fundamental shock $\phi_{i j}$ and transitory fundamental shock $\psi_{i j}$. Since noise traders respond to all three shocks, we decompose 
noise traders' reservation price change $\Delta P_{i n}^{*}$ into permanent fundamental shocks $\phi_{i j}$, transitory fundamental shocks $\psi_{i j}$, and non-fundamental shocks $\eta_{i n}$.

Since informed traders are homogenous, $\phi_{i j}$ and $\psi_{i j}$ are the same for all informed traders. Hence $\phi_{i}$ and $\psi_{i}$ can be used in equation (8) whenever applicable. The informed traders' reservation price change $\Delta P_{i j}^{*}$ is therefore based on $\phi_{i}$ and $\psi_{i}$. According to the assumptions laid out above, noise traders would have the same responses as informed traders if noise traders could single out fundamental shocks from non-fundamental shocks. Therefore, $\phi_{i j}$ and $\psi_{i j}$ can also be replaced by $\phi_{i}$ and $\psi_{i}$ respectively. However, since noise traders do not actually have the ability to single out fundamental shocks from non-fundamental ones, their reservation prices differ from those of informed traders by $\eta_{i n}$. Moreover, $\eta_{i n}$ is different across noise traders since noise traders are heterogeneous and have different sensitivities to noise (non-fundamental shocks) according to Kelly (1997). Taking this into consideration, we base the noise traders' reservation price change $\Delta P_{i j}^{*}$ on $\phi_{i}, \psi_{i}$ and $\eta_{i n}$. We assume that $\phi, \psi$, and $\eta$ are mutually independent, both across traders and through time.

Based on the above argument, equation (8) can be rewritten as

$$
\begin{aligned}
& \Delta P_{i j}^{*}=\phi_{i}+\psi_{i}, \quad \Delta P_{i n}^{*}=\phi_{i}+\psi_{i}+\eta_{i n} \\
& E\left(\phi_{i}\right)=E\left(\psi_{i}\right)=E\left(\eta_{i n}\right)=0, \quad \operatorname{var}\left(\phi_{i}\right) \equiv \sigma_{\phi}^{2}, \quad \operatorname{var}\left(\psi_{i}\right) \equiv \sigma_{\psi}^{2}, \quad \operatorname{var}\left(\eta_{i n}\right) \equiv \sigma_{\eta}^{2}
\end{aligned}
$$

Using the variance-components model of equation (9), the aggregate $i^{\text {th }}$ price change and trading volume can be written as

$$
\begin{aligned}
& \Delta P_{i}=\phi_{i}+\psi_{i}+\bar{\eta}_{i}, \quad \bar{\eta}_{i}=\frac{1}{J+N} \sum_{n=1}^{N} \eta_{i n} \\
& \sigma_{\Delta p}^{2}=\operatorname{var}\left[\Delta P_{i}\right]=\sigma_{\phi}^{2}+\sigma_{\psi}^{2}+\frac{N}{(J+N)^{2}} \sigma_{\eta}^{2} \\
& V_{i}=\frac{a}{2} \sum_{j=1}^{J}\left|\eta_{i}\right|+\frac{a}{2} \sum_{n=1}^{N}\left|\eta_{i n}-\eta_{i}\right|
\end{aligned}
$$

Proof (See Appendix C)

Equation (10) gives us a one-period model for returns, volatility and volume. Within a day the market passes through a total of I sequence of equilibriums, as has been modeled by equation (9). The daily price change is the sum of $\Delta p_{i}$, that is $\Delta p=\sum_{i=1}^{I} \Delta p_{i}$ where I is the total number of equilibriums throughout a day. Daily price change, volatility and volume can be written as a multi-period daily model of returns, volatility, and volume, which is represented as 


$$
\begin{aligned}
& \Delta p=\sum_{i}^{I} \phi_{i}+\sum_{i}^{I} \psi_{i}+\sum_{i}^{I} \bar{\eta}_{i} \\
& \sigma_{\Delta p}^{2}=\operatorname{var}[\Delta p]=\sum_{i}^{I} \sigma_{\phi}^{2}+\sum_{i}^{I} \sigma_{\psi}^{2}+\sum_{i}^{I} \frac{N}{(J+N)^{2}} \sigma_{\eta}^{2} \\
& V=\frac{a}{2} \sum_{i}^{I} \sum_{j=1}^{J}\left|\eta_{i}\right|+\frac{a}{2} \sum_{i}^{I} \sum_{n=1}^{N}\left|\eta_{i n}-\eta_{i}\right|
\end{aligned}
$$

Proof (See Appendix D)

In equation (11), trading volume is divided into two parts: volume generated when noise traders fulfill orders from informed traders, $\frac{a}{2} \sum_{i}^{I} \sum_{j=1}^{J}\left|\bar{\eta}_{i}\right|$, and volume produced when noise traders fulfill each other's orders, $\frac{a}{2} \sum_{i}^{I} \sum_{n=1}^{N}\left|\eta_{i n}-\eta_{i}\right|$

According to equation (11), permanent and transitory fundamental shocks, $\phi_{i}$ and $\psi_{i}$, do not play any role in the generation of contemporaneous trading volume, but they do play significant roles in the generation of contemporaneous returns and volatility. Non-fundamental shocks $\eta_{i n}$ impact upon all areas: the generation of returns, volatility, and volume. The observation from equation (11) that only contemporaneous non-fundamental shocks play a role in the generation of trading volume is supported by Black (1986), who asserts that noise (nonfundamental shocks) makes financial markets possible and that without noise there would be no trading. This is consistent with He and Wang's (1995) finding that under a homogenous information setting, volume reflects only non-fundamental trading. This is also supported by Lee and Rui (2001), who argue that "the non-fundamental shock should affect trading volume, while the informational shock does not."

The trivariate multi-period daily model of returns, volatility, and volume presented in equation (11) reveals that permanent fundamental and transitory fundamental shocks do not have any contemporaneous effects on trading volume. Furthermore, by construction, the cumulative effects of transitory fundamental shocks on returns should be zero in the long run, which distinguishes transitory shocks from permanent ones. Note that since equation (11) is a multi-period daily model, the long run effects of transitory fundamental shocks on returns are not directly observable.

We have thus identified three restrictions from the trivariate multi-period daily model: (1) the cumulative effects of transitory fundamental shocks on returns are zero; (2) permanent fundamental shocks have no contemporaneous effects on trading volume; and (3) transitory fundamental shocks have no contemporaneous effects on trading volume. These restrictions are consistent with those assumptions used in Sun (2008). This paper therefore provides a theoretical model that is consistent with the empirical evidence of Sun (2008). A trivariate structural vector autoregressive (SVAR) model can be used to test the validity of the model while incorporating all three types of shocks and applying the three restrictions. 


\section{APPLICATION}

In this section, we use Microsoft data from January 1998 to December 2006 to show how to apply our model. Daily returns and daily trading volume (proxied by turnover ratio) are obtained from the CRSP database, and the intra-day data are taken from R.C. Research.

The trivariate SVAR model can be written in the following format:

$$
\left[\begin{array}{c}
r_{t} \\
\sigma_{t} \\
v_{t}
\end{array}\right]=\left[\begin{array}{c}
\sum_{k} a_{11}(k) n_{t-k}+\sum_{k} a_{12}(k) p_{t-k}+\sum_{k} a_{13}(k) t_{t-k} \\
\sum_{k} a_{21}(k) n_{t-k}+\sum_{k} a_{22}(k) p_{t-k}+\sum_{k} a_{23}(k) t_{t-k} \\
\sum_{k} a_{31}(k) n_{t-k}+\sum_{k} a_{32}(k) p_{t-k}+\sum_{k} a_{33}(k) t_{t-k}
\end{array}\right]
$$

where $r_{t}, \sigma_{t}$ and $v_{t}$ represent the daily return, daily volatility, and daily trading volume, $p_{t}, t_{t}$ and $n_{t}$ are permanent fundamental shock, transitory fundamental shock, and non-fundamental shock respectively, which are serially and contemporaneously uncorrelated by construction. The variance of the vector $e_{t}=\left[\begin{array}{lll}n_{t} & p_{t} & t_{t}\end{array}\right]^{\prime}$ is assumed to be the identity matrix of rank 3 by normalization.

We propose to use transaction level data to estimate daily volatility as in Anderson and Bollerslev (1998). The following equation is used:

$$
\sigma_{i t}=\frac{1}{\sqrt{2 n / \pi}} \sum_{p=1}^{n}\left|R_{i t p}\right|
$$

where $\sigma_{i t}$ represents the daily volatility of security i on day $\mathrm{t}, R_{i t p}$ respresents the return of security $\mathrm{i}$ at the $\mathrm{p}^{\text {th }}$ five-minute horizon ${ }^{6}$ on day $\mathrm{t}$, and $\bar{R}_{i t}=\frac{1}{n} \sum_{p=1}^{n} R_{i t p}$, where $n$ is the number of five-minute intervals on day t.

The three restrictions obtained from the theoretical model can be written, respectively, as

$$
\sum_{k} a_{13}(k)=0, a_{32}(0)=0, a_{33}(0)=0
$$

After imposing the three identifying restrictions in equation (14) onto the SVAR model in equation (12), we use a Blanchard-Quah type decomposition to examine the relative importance of each shock for returns, volatility, and volume? ${ }^{7}$. The SVAR forecast error decomposition results for Microsoft are presented in table 1 and graphed in figure 1 .

As shown in the table and graph, trading volume is primarily affected by non-fundamental shocks. Even after 30 days, the effect of non-fundamental shocks on trading volume still amounts to about $96.4 \%$. Contemporaneously, permanent and transitory fundamental shocks have no effects on trading volume, as predicted by the theoretical model. However, when the forecast horizon increases, permanent fundamental and transitory fundamental shocks start to influence trading volume, although the influence is very minimal, about $2 \%$ after 30 days. This finding is not contradictory to the theoretical model at all. The theoretical model only states that permanent and transitory fundamental shocks do not affect trading volume contemporaneously. It is very possible that permanent fundamental and transitory fundamental shocks have a lagged effect on trading volume, as proven by the empirical results here. 
According to the theoretical model, returns are affected by all three shocks, with transitory fundamental shocks having a zero long-run cumulative effect. As displayed in the table and on the graph, permanent fundamental shocks prove to be the most important contributors to returns, with more than $96 \%$ of the variation of returns due to permanent fundamental shocks even after 30 days. Transitory fundamental shocks play a very minimal role in the return process. Only $2.3 \%$ of the returns can be attributed to transitory fundamental shocks initially. Even when forecast horizon increases, this figure increases to only about $6 \%$ after 30 days. This finding confirms the theoretical model that transitory fundamental shocks have no long-run cumulative effects on returns. Non-fundamental shocks contribute even less in the return process. Their initial effect is less than $0.1 \%$, with no significant increases in the 30 day horizon, which leads us to believe that Microsoft stock returns are not very sensitive to noise trading.

As far as volatility is concerned, the theoretical model hypothesizes that all three types of shocks affect volatility, which is confirmed by our empirical results. However, the relative importance of each shock on volatility varies. Transitory fundamental shocks are the most important contributor to volatility. About $90 \%$ of the volatility can be explained by transitory fundamental shocks initially. As forecast horizon increases, about $85 \%$ of the volatility can still be explained by transitory fundamental shocks after 30 days. About $10 \%$ of the volatility can be attributed to non-fundamental shocks initially, though the impact decreases over time, to about $6.1 \%$ after 30 days. However, the effect of permanent fundamental shocks on volatility increases over time, reaching about $9.3 \%$ after 30 days.

Table 1: Variance decomposition of returns, volatility, and volume for MSFT

This table reports the relative importance of each shock in explaining returns, volatility, and volume in the SVAR model for various (1 through 30 days) forecasting horizons. $p_{t}$ represents permanent fundamental shocks, $t_{t}$ represents transitory fundamental shocks, and $n_{t}$ represents non-fundamental shocks.

\begin{tabular}{cccccccccc}
\hline MSFT & \multicolumn{9}{c}{ Variables Explained } \\
\hline \multirow{3}{*}{$\begin{array}{c}\text { Forecast } \\
\text { Horizons }\end{array}$} & \multicolumn{3}{c}{ Volume } & \multicolumn{3}{c}{ Return } & \multicolumn{3}{c}{ Volatility } \\
\cline { 2 - 10 } & $n_{t}$ & $p_{t}$ & $t_{t}$ & $n_{t}$ & $p_{t}$ & $t_{t}$ & $n_{t}$ & $p_{t}$ & $t_{t}$ \\
\hline 1 & 100.0 & 0.0 & 0.0 & 0.1 & 97.6 & 2.3 & 10.0 & 0.0 & 90.0 \\
2 & 99.9 & 0.0 & 0.1 & 0.3 & 97.3 & 2.4 & 10.9 & 2.8 & 86.3 \\
3 & 99.6 & 0.2 & 0.2 & 0.3 & 97.2 & 2.5 & 11.2 & 4.3 & 84.5 \\
4 & 99.4 & 0.4 & 0.2 & 0.3 & 97.2 & 2.5 & 10.8 & 5.7 & 83.5 \\
5 & 99.4 & 0.4 & 0.2 & 0.4 & 97.1 & 2.6 & 11.0 & 6.4 & 82.7 \\
6 & 99.1 & 0.7 & 0.2 & 0.4 & 97.0 & 2.6 & 10.7 & 6.6 & 82.7 \\
7 & 98.9 & 0.8 & 0.3 & 0.5 & 96.9 & 2.7 & 10.2 & 6.7 & 83.1 \\
8 & 98.6 & 1.0 & 0.3 & 0.7 & 96.6 & 2.8 & 9.9 & 6.8 & 83.4 \\
9 & 98.6 & 1.0 & 0.4 & 0.7 & 96.5 & 2.8 & 9.5 & 7.2 & 83.3 \\
10 & 98.2 & 1.4 & 0.4 & 0.7 & 96.4 & 2.9 & 9.1 & 7.9 & 83.0 \\
20 & 97.1 & 1.8 & 1.1 & 1.0 & 96.0 & 3.0 & 7.1 & 8.9 & 84.0 \\
30 & 96.4 & 1.9 & 1.7 & 1.0 & 96.0 & 3.0 & 6.1 & 9.3 & 84.6 \\
\hline
\end{tabular}


Figure 1: Variance decomposition for MSFT

This figure illustrates the relative importance of permanent fundamental, transitory fundamental, and non-fundamental shocks to returns, volatility, and trading volume using variance decomposition. (Black: non-fundamental shocks; dark grey: transitory fundamental shocks; light grey: permanent fundamental shocks)
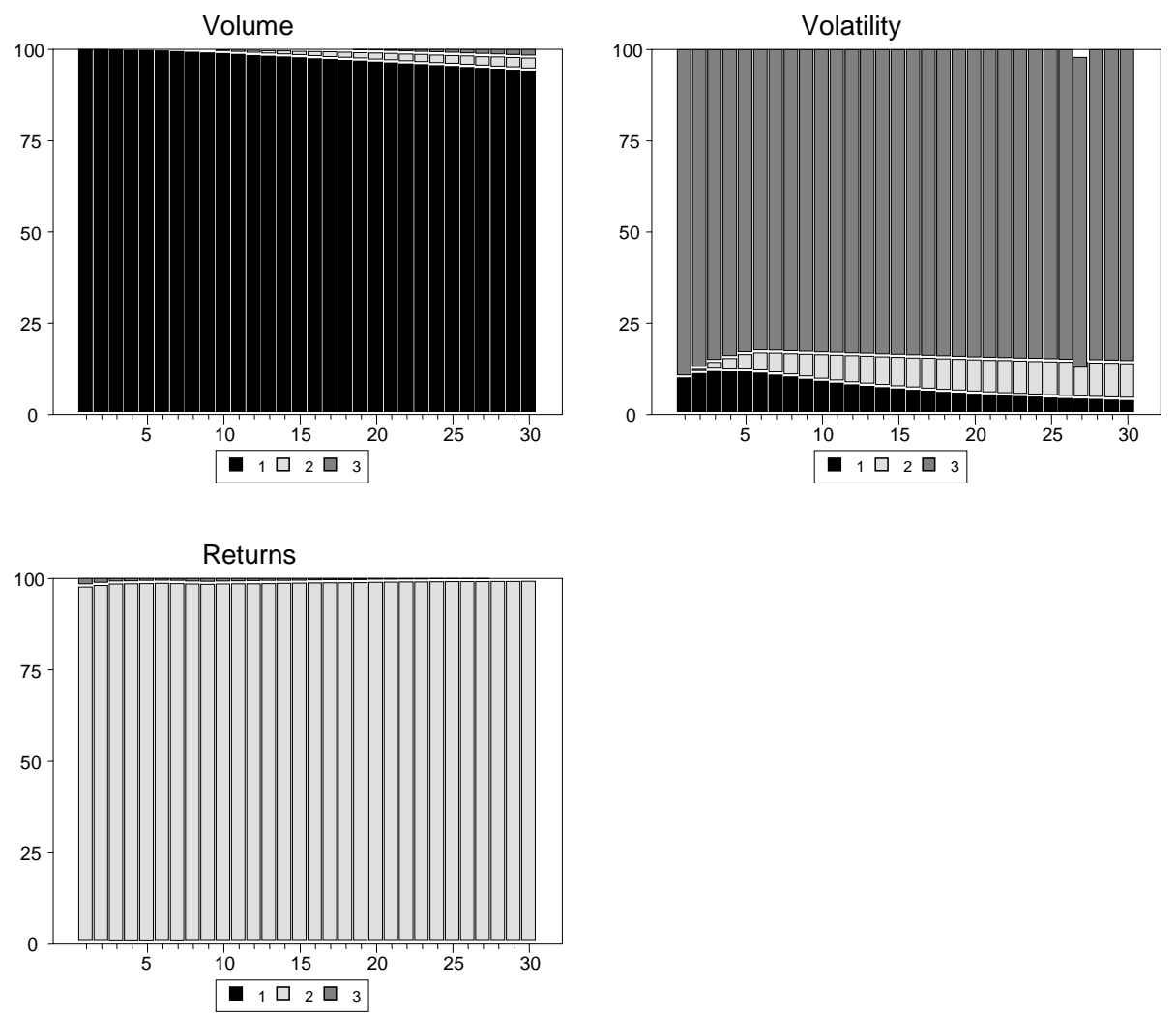

In summary, permanent fundamental shocks mainly affect returns, while transitory fundamental shocks primarily affect volatility. Non-fundamental shocks mostly impact volume. De Long et al. (1990) show that noise trading risks that arise from non-fundamental shocks are market-wide and could not be diversified away. The decomposition used here is very helpful for investors to find out how sensitive the stock returns are to nonfundamental shocks. It provides investors with an approach to identify those stocks with higher/lower noise trader risk and construct their portfolios accordingly.

\section{CONCLUSION}

This paper constructs a theoretical model to describe the impacts of permanent fundamental, transitory fundamental, and non-fundamental shocks on returns, volatility and volume. This model provides three identifying restrictions to distinguish the three shocks, which can be applied to a trivariate SVAR model to empirically identify the impacts of the three shocks on trading dynamics. We find that the main drivers for returns are permanent fundamental shocks, while the main drivers for volatility are transitory fundamental shocks. Non-fundamental shocks are the major drivers for the trading volume. 


\section{AUTHOR INFORMATION}

Megan Y. Sun, Ph.D., is the Assistant Professor of Finance in the Department of Accounting and Finance at the University of Wisconsin - River Falls. Her research interests include asset pricing, market efficiency, market microstructure, derivatives, and behavioral finance.

\section{REFERENCES}

1. Admati, A. R., and P. Pfleiderer (1988), "A theory of intra-day patterns: volume and price variability," Review of Financial Studies 1 (No. 1, January), pp. 3-40.

2. $\quad$ Ait-Sahalia, Y. (1998), "Dynamic equilibrium and volatility in financial asset markets," Journal of Econometrics 84 (No. 1, May), pp. 93-127.

3. Anderson, T. (1996), "Return volatility and trading volume: an information flow interpretation of stochastic volatility," Journal of Finance 51 (No. 1, March), pp. 169-204.

4. Andersen, T. G., and T. Bollerslev. (1998). "Deutsche mark-dollar volatility: intraday activity patters, macroeconomic announcements, and longer run dependences." Journal of Finance, vol. 53 (February 1998), pp. 219-265.

5. Anderson, T., T. Bollerslev, F. Diebold, and E. Keiko (2001), "The distribution of realized stock return volatility," Journal of Financial Economics 61 (No. 1, July), pp. 43-76.

6. $\quad$ Black, F. (1986), "Noise," Journal of Finance 41 (No. 3, July), pp. 529-543.

7. Blanchard, O. J., and D. Quah (1989), "The dynamic effects of aggregate demand and supply disturbances," The American Economic Review 79 (No. 4, September), pp. 655-673.

8. Blume, L., D. Easley, and M. O'Hara (1994), "Market statistics and technical analysis: the role of volume," Journal of Finance 49 (No. 1, March), pp.153-181.

9. Campbell, J., S. Grossman, and J. Wang (1993), "Trading volume and serial correlation in stock returns," Quarterly Journal of Economics 108 (No. 4, November), pp. 905-939.

10. Clark, P. K. (1973), "A subordinated stochastic process with finite variances for speculative prices," Econometrica 41 (No. 1, January), pp. 3-32.

11. De Long, J. B., A. Shleifer, L. H. Summers, and R. J. Waldman (1990), "Noise trader risk in financial markets," Journal of Political Economy 98 (No. 4, August), pp. 703-738.

12. Epps, T. W. and M. L. Epps (1976), "The stochastic dependence of security price changes and transaction volumes: implications for the mixture-of-distributions hypothesis," Econometrica 44 (No. 2, March), pp. 305-321.

13. Fleming, J., C. Kirby, and B. Ostdiek (2001), "Stochastic volatility, trading volume, and the daily flow of information," Journal of Business 79 (No. 3, May), pp. 1551-1590.

14. Foster, F. D., and S. Viswanathan (1993), "Variations in trading volume, return volatility, and trading costs: evidence on recent price formation models," Journal of Finance 48 (No. 1, March), pp. 187-211.

15. Foster, F. D., and S. Viswanathan (1995), "Can speculative trading explain the volume-volatility relation?" Journal of Business and Economic Statistics 13 (No. 4, October), pp. 379-396.

16. Gallant, A. R., P. E. Rossi, and G. Tauchen (1992), "Stock prices and volume," Review of Financial Studies 5 (No. 2, April), pp. 199-242.

17. Harris, L. (1987), "Transaction data tests of the mixture of distributions hypothesis," Journal of Financial and Quantitative Analysis 22 (No. 2, June), pp. 127-141.

18. He, H. and J. Wang (1995), "Differential information and dynamic behavior of stock trading volume," Review of Financial Studies 8 (No. 4, Winter), pp. 919-972.

19. Kelly, M. (1997), "Do noise traders influence stock prices?” Journal of Money, Credit, and Banking 29 (No. 3, August), pp. 369-386.

20. Kyle, A. S. (1985), “Continuous auctions and insider trading," Econometrica 53 (No. 6, November), pp. 1315-1335.

21. Lamoureux, C., and W. Lastrapes (1990), "Heteroskedasticity in stock return data: volume versus GARCH effects," Journal of Finance 45 (No. 1, March), pp. 221-229.

22. Lamoureux, C., and W. Lastrapes (1994), "Endogenous trading volume and momentum in stock-return volatility," Journal of Business and Economic Statistics 12 (No. 2, April), pp. 253-260. 
23. Lee, B. (1998), "Permanent, temporary, and non-fundamental components of stock prices," Journal of Financial and Quantitative Analysis 33 (No. 1, March), pp. 1-32.

24. Lee, B., and O. M. Rui (2001), "Empirical identification of non-informational trades using trading volume data," Review of Quantitative Finance and Accounting 17 (No. 4, December), pp. 327-350.

25. Liesenfeld, R. (1998), "Dynamic bivariate mixture models: modelling the behavior of prices and trading volume," Journal of Business and Economic Statistics 16 (No. 1, January), pp. 101-109.

26. Liesenfeld, R. (2001), "A generalized bivariate mixture model for stock price volatility and trading volume," Journal of Econometrics 104 (No. 1, August), pp. 141-178.

27. Mahieu, R., and B. Bauer (1998), "A Bayesian analysis of stock return volatility and trading volume," Applied Financial Economics 8 (No. 6, December), pp. 671-687.

28. Richardson, M., and T. Smith (1994), "A direct test of the mixture of distributions hypothesis: measuring the daily flow of information," Journal of Financial and Quantitative Analysis 29 (No. 1, March), pp. 101116.

29. Sun, Megan (2008), "Permanent, transitory, and non-fundamental components of returns, volatility, and volume," Journal of Business and Economic Research 6 (No. 6, June), pp. 73-86.

30. Tauchen, G., and M. Pitts (1983), "The price variability-volume relationship on speculative markets," Econometrica 51 (No. 2, March), pp. 485-505.

31. Tauchen, G., H. Zhang, and M. Liu (1996), "Volume, volatility, and leverage: a dynamic analysis," Journal of Econometrics 74 (No. 1, September), pp. 177-208.

32. Wang, J. (1994), “A model of competitive stock trading volume," Journal of Political Economy 102 (No. 1, February), pp. 127-168.

33. Watanabe, T. (2000), "Bayesian analysis of dynamic bivariate mixture models: Can they explain the behavior of returns and trading volume?" Journal of Business \& Economic Statistics 18 (No. 2, April), pp. 199-210.

\section{Endnotes:}

${ }^{1}$ According to Kelly (1997), high-income investors tend to be smart money, while low-income investors tend to be noise traders.

${ }^{2}$ Sun (2008) also applies a VAR model to test the impact of permanent, transitory, and non-fundamental shocks on returns, volatility, and volume. However, Sun (2008) mainly focuses on the empirical testing and doesn't provide us with a theoretical model, which is exactly the void this paper tries to fill.

${ }^{3}$ In addition to the mixture of distributions model, other approaches have been taken to explain the returns and volume formation process. For instance, Gallant, Rossi, and Tauchen (1992) and Tauchen, Zhang, and Liu (1996) use a nonparametric approach. Admati and Pfleiderer (1988), Foster and Viswanathan (1995), Blume, Easley, and O'Hara (1994), Wang (1994), and Ait-Sahalia (1998) use a microstructure approach based on the essence of Kyle (1985).

${ }^{4}$ Tauchen and Pitts (1983) assume that the market consists of J traders. They do not distinguish between informed traders and noise traders.

${ }^{5}$ We assume that informed traders and noise traders have the same coefficients of absolute risk aversion. For the same amount of perceived price change, informed traders and noise traders have the same response about how much they want to change their positions. Noise traders could have the same coefficients of absolute risk aversion as the informed traders because when noise traders trade, they think they are trading on fundamental information and they are confident in their stock valuation just as informed traders are.

${ }^{6}$ According to Anderson et al. (2001) using 5-minute interval data could mitigate the discrete clustering and bid-ask bounce effects associated with transaction prices, a problem that can seriously distort the distributional properties of high-frequency intra-day return. 
${ }^{7}$ Since SVAR analysis requires all variables to be stationary to avoid spurious regression problems, Augmented Dickey-Fuller (ADF) and Phillips-Perron (PP) tests are used to test the stationarity of the input variables. Test results, which are available upon request, show that all series are stationary.

Appendix A: Proof of Equation (4) $\Delta P_{i}=\frac{1}{J+N}\left(\sum_{j=1}^{J} \Delta P_{i j}^{*}+\sum_{n=1}^{N} \Delta P_{i n}^{*}\right)$

The requirements for the $i$ th equilibrium, in which the total number of buy orders must match the total number of sell orders, is given by equation (3)

$\sum_{j=1}^{J}\left(Q_{i j}-Q_{(i-1) j}\right)+\sum_{n=1}^{N}\left(Q_{i n}-Q_{(i-1) n}\right)=0$

where $Q_{i j}=a\left[P_{i j}^{*}-P_{i}\right]$ as given by equation (1), is the desired position change for the $j$ th informed trader, and $Q_{i n}=a\left[P_{i n}^{*}-P_{i}\right]$ as given by equation (2), is the desired position change for the $n$th noise trader.

When we plug (1) and (2) into equation (3), we get

$\sum_{j=1}^{J}\left\{a\left[P_{i j}^{*}-P_{i}\right]-a\left[P_{(i-1) j}^{*}-P_{i-1}\right]\right\}+\sum_{n=1}^{N}\left\{a\left[P_{i n}^{*}-P_{i}\right]-a\left[P_{(i-1) n}^{*}-P_{i-1}\right]\right\}=0$

Since $a>0$ is a constant, then

$\sum_{j=1}^{J}\left\{a\left[P_{i j}^{*}-P_{i}-P_{(i-1) j}^{*}+P_{i-1}\right]\right\}+\sum_{n=1}^{N}\left\{a\left[P_{i n}^{*}-P_{i}-P_{(i-1) n}^{*}+P_{i-1}\right]\right\}=0$

As has been defined by equation (35),

$\Delta P_{i j}^{*}=P_{i j}^{*}-P_{(i-1) j}^{*}, \Delta P_{i n}^{*}=P_{i n}^{*}-P_{(i-1) n}^{*}$ and $\Delta P_{i}=P_{i}-P_{(i-1)}$

We can rewrite (E-2) as

$\sum_{j=1}^{J}\left\{a\left[\Delta P_{i j}^{*}-\Delta P_{i}\right]\right\}+\sum_{n=1}^{N}\left\{a\left[\Delta P_{i n}^{*}-\Delta P_{i}\right]\right\}=0$

Then

$a \sum_{j=1}^{J}\left[\Delta P_{i j}^{*}\right]-a J \Delta P_{i}+a \sum_{j=1}^{J}\left[\Delta P_{i n}^{*}\right]-a N \Delta P_{i}=0$

then

$a(J+N) \Delta P_{i}=a \sum_{j=1}^{J} \Delta P_{i j}^{*}+a \sum_{n=1}^{N} \Delta P_{i n}^{*}$

then

$\Delta P_{i}=\frac{1}{J+N}\left(\sum_{j=1}^{J} \Delta P_{i j}^{*}+\sum_{n=1}^{N} \Delta P_{i n}^{*}\right)$ 
Appendix B: Proof of Equation (7) $V_{i}=\frac{a}{2} \sum_{j=1}^{J}\left|\Delta P_{i j}^{*}-\Delta P_{i}\right|+\frac{a}{2} \sum_{n=1}^{N}\left|\Delta P_{i n}^{*}-\Delta P_{i}\right|$

As has been defined by equation (6), the trading volume is half of the total position change.

$V_{i}=\frac{1}{2} \sum_{j=1}^{J}\left|Q_{i j}-Q_{(i-1) j}\right|+\frac{1}{2} \sum_{n=1}^{N}\left|Q_{i n}-Q_{(i-1) n}\right|$

where $Q_{i j}=a\left[P_{i j}^{*}-P_{i}\right]$ as given by equation (1), is the desired position change for the $j$ th informed trader, and $Q_{i n}=a\left[P_{i n}^{*}-P_{i}\right]$ as given by equation (2), is the desired position change for the $n$th noise trader.

When we plug (1) and (2) into equation (6), we get

$V_{i}=\frac{1}{2} \sum_{j=1}^{J}\left|a\left[P_{i j}^{*}-P_{i}\right]-a\left[P_{(i-1) j}^{*}-P_{i-1}\right]+\frac{1}{2} \sum_{n=1}^{N}\right| a\left[P_{i n}^{*}-P_{i}\right]-a\left[P_{(i-1) n}^{*}-P_{i-1}\right]$

Since $a>0$ is a constant, then

$V_{i}=\frac{1}{2} \sum_{j=1}^{J}\left|a\left[P_{i j}^{*}-P_{i}-P_{(i-1) j}^{*}+P_{i-1}\right]+\frac{1}{2} \sum_{n=1}^{N}\right| a\left[P_{i n}^{*}-P_{i}-P_{(i-1) n}^{*}+P_{i-1}\right]$

Then

$V_{i}=\frac{a}{2} \sum_{j=1}^{J}\left|\left[P_{i j}^{*}-P_{(i-1) j}^{*}-P_{i}+P_{i-1}\right]+\frac{a}{2} \sum_{n=1}^{N}\right|\left[P_{i n}^{*}-P_{(i-1) n}^{*}-P_{i}+P_{i-1}\right]$

As has been defined by equation (5),

$$
\Delta P_{i j}^{*}=P_{i j}^{*}-P_{(i-1) j}^{*}, \Delta P_{i n}^{*}=P_{i n}^{*}-P_{(i-1) n}^{*} \text { and } \Delta P_{i}=P_{i}-P_{(i-1)}
$$

We can then rewrite (B-3) as

$V_{i}=\frac{a}{2} \sum_{j=1}^{J}\left|\Delta P_{i j}^{*}-\Delta P_{i}\right|+\frac{a}{2} \sum_{n=1}^{N}\left|\Delta P_{i n}^{*}-\Delta P_{i}\right|$

Appendix C: Proof of Equation (10): The One-Period Model

According to the variance-components model given by equation (9) 
$\Delta P_{i j}^{*}=\phi_{i}+\psi_{i}, \quad \Delta P_{i n}^{*}=\phi_{i}+\psi_{i}+\eta_{i n}$

$E\left(\phi_{i}\right)=E\left(\psi_{i}\right)=E\left(\eta_{\text {in }}\right)=0, \quad \operatorname{var}\left(\phi_{i}\right) \equiv \sigma_{\phi}^{2}, \quad \operatorname{var}\left(\psi_{i}\right) \equiv \sigma_{\psi}^{2}, \quad \operatorname{var}\left(\eta_{\text {in }}\right) \equiv \sigma_{\eta}^{2}$

(1) Proof of the price change:

Given equation (4): $\Delta P_{i}=\frac{1}{J+N}\left(\sum_{j=1}^{J} \Delta P_{i j}^{*}+\sum_{n=1}^{N} \Delta P_{i n}^{*}\right)$

When we plug equation (9) into equation (4), we get

$$
\Delta P_{i}=\frac{1}{J+N}\left(\sum_{j=1}^{J}\left(\phi_{i}+\psi_{i}\right)+\sum_{n=1}^{N}\left(\phi_{i}+\psi_{i}+\eta_{i n}\right)\right)
$$

Then

$$
\Delta P_{i}=\frac{1}{J+N}\left(J \phi_{i}+J \psi_{i}+N \phi_{i}+N \psi_{i}+\sum_{n=1}^{N} \eta_{i n}\right)
$$

Then

$$
\Delta P_{i}=\frac{1}{J+N}\left((J+N) \phi_{i}+(J+N) \psi_{i}+\sum_{n=1}^{N} \eta_{i n}\right)
$$

Then

$$
\Delta P_{i}=\phi_{i}+\psi_{i}+\frac{1}{J+N} \sum_{n=1}^{N} \eta_{i n}
$$

if $\bar{\eta}_{i}=\frac{1}{J+N} \sum_{n=1}^{N} \eta_{i n}$, then

$$
\Delta p_{i}=\phi_{i}+\psi_{i}+\bar{\eta}_{i}, \quad \bar{\eta}_{i}=\frac{1}{J+N} \sum_{n=1}^{N} \eta_{i n}
$$

(2) Proof of the variance of price change:

Correspondingly, the variance of price change is

$$
\sigma_{\Delta p}^{2}=\operatorname{var}\left[\Delta p_{i}\right]=\operatorname{var}\left[\phi_{i}+\psi_{i}+\bar{\eta}_{i}\right]
$$

Since $\phi, \psi$, and $\eta$ are mutually independent, both across traders and through time

$$
\sigma_{\Delta p}^{2}=\operatorname{var}\left[\phi_{i}\right]+\operatorname{var}\left[\psi_{i}\right]+\operatorname{var}\left[\bar{\eta}_{i}\right]
$$




$$
\sigma_{\Delta p}^{2}=\operatorname{var}\left[\phi_{i}\right]+\operatorname{var}\left[\psi_{i}\right]+\operatorname{var}\left[\frac{1}{J+N} \sum_{n=1}^{N} \eta_{i n}\right]
$$

As has been defined by equation (9)

$$
\operatorname{var}\left(\phi_{i}\right) \equiv \sigma_{\phi}^{2}, \quad \operatorname{var}\left(\psi_{i}\right) \equiv \sigma_{\psi}^{2}, \quad \operatorname{var}\left(\eta_{i n}\right) \equiv \sigma_{\eta}^{2}
$$

hence

$$
\sigma_{\Delta p}^{2}=\operatorname{var}\left[\Delta p_{i}\right]=\sigma_{\phi}^{2}+\sigma_{\psi}^{2}+\frac{N}{(J+N)^{2}} \sigma_{\eta}^{2}
$$

(3) Proof of the trading volume:

As has been given by equation (7)

$V_{i}=\frac{a}{2} \sum_{j=1}^{J}\left|\Delta P_{i j}^{*}-\Delta P_{i}\right|+\frac{a}{2} \sum_{n=1}^{N}\left|\Delta P_{i n}^{*}-\Delta P_{i}\right|$

Equation (9) formulates:

$$
\Delta P_{i j}^{*}=\phi_{i}+\psi_{i}, \quad \Delta P_{i n}^{*}=\phi_{i}+\psi_{i}+\eta_{i n}
$$

and the first equation of (10) states: $\Delta p_{i}=\phi_{i}+\psi_{i}+\bar{\eta}_{i}$

When we plug (9) and (10) into (7), equation (7) can be rewritten as:

$V_{i}=\frac{a}{2} \sum_{j=1}^{J}\left|\left(\phi_{i}+\psi_{i}\right)-\left(\phi_{i}+\psi_{i}+\bar{\eta}\right)\right|+\frac{a}{2} \sum_{n=1}^{N}\left|\left(\phi_{i}+\psi_{i}+\eta_{i n}\right)-\left(\phi_{i}+\psi_{i}+\bar{\eta}\right)\right|$

then

$$
V_{i}=\frac{a}{2} \sum_{j=1}^{J}\left|\overline{\eta_{i}}\right|+\frac{a}{2} \sum_{n=1}^{N}\left|\eta_{i n}-\bar{\eta}_{i}\right|
$$

Appendix D: Proof of Equation (11): The Daily Model

(1) Proof of daily price change:

According to the one-period model of returns, volatility and volume as given in equation (10) are

$$
\Delta p_{i}=\phi_{i}+\psi_{i}+\bar{\eta}_{i}, \quad \bar{\eta}_{i}=\frac{1}{J+N} \sum_{n=1}^{N} \eta_{i n}
$$

The daily price change is the sum of single-period price change, $\Delta p_{i}$, 
Therefore,

$\Delta p=\sum_{i=1}^{I} \Delta p_{i}$ where I is the total number of equilibriums throughout a day,

then,

$\Delta p=\sum_{i=1}^{I} \Delta p_{i}=\sum_{i=1}^{I}\left(\phi_{i}+\psi_{i}+\bar{\eta}_{i}\right)$

Since $\phi, \psi$, and $\eta$ are mutually independent, both across traders and through time, then

$\Delta p=\sum_{i}^{I} \phi_{i}+\sum_{i}^{I} \psi_{i}+\sum_{i}^{I} \bar{\eta}_{i}$

(2) Proof of daily volatility:

According to (11)

$\Delta p=\sum_{i}^{I} \phi_{i}+\sum_{i}^{I} \psi_{i}+\sum_{i}^{I} \bar{\eta}_{i}$

where $\bar{\eta}_{i}=\frac{1}{J+N} \sum_{n=1}^{N} \eta_{i n}$

When we plug (D-3) into (D-2)

$\Delta p=\sum_{i}^{I} \phi_{i}+\sum_{i}^{I} \psi_{i}+\sum_{i}^{I}\left\{\frac{1}{J+N} \sum_{n=1}^{N} \eta_{i n}\right\}$

As given by equation (9),

$E\left(\phi_{i}\right)=E\left(\psi_{i}\right)=E\left(\eta_{i n}\right)=0, \quad \operatorname{var}\left(\phi_{i}\right) \equiv \sigma_{\phi}^{2}, \quad \operatorname{var}\left(\psi_{i}\right) \equiv \sigma_{\psi}^{2}, \quad \operatorname{var}\left(\eta_{\text {in }}\right) \equiv \sigma_{\eta}^{2}$

then

$\sigma_{\Delta p}^{2}=\operatorname{var}[\Delta p]=\sum_{i}^{I} \operatorname{var}\left(\phi_{i}\right)+\sum_{i}^{I} \operatorname{var}\left(\psi_{i}\right)+\sum_{i}^{I} \frac{N}{(J+N)^{2}} \operatorname{var}\left(\eta_{i}\right)$

then

$\sigma_{\Delta p}^{2}=\operatorname{var}[\Delta p]=\sum_{i}^{I} \sigma_{\phi}^{2}+\sum_{i}^{I} \sigma_{\psi}^{2}+\sum_{i}^{I} \frac{N}{(J+N)^{2}} \sigma_{\eta}^{2}$

(3) Proof of daily volume:

According to the one-period model of equation (10)

$V_{i}=\frac{a}{2} \sum_{j=1}^{J}\left|\bar{\eta}_{i}\right|+\frac{a}{2} \sum_{n=1}^{N}\left|\eta_{i n}-\bar{\eta}_{i}\right|$ 
Since the daily volume $V$ is the sum of single-period trading volume, $V_{i}$, then

$V=\sum_{i}^{I} V_{i}$

where $\mathrm{I}$ is the total number of equilibriums throughout a day.

When we plug (10) into (D-7)

$V=\sum_{i}^{I}\left\{\frac{a}{2} \sum_{j=1}^{J}\left|\bar{\eta}_{i}\right|+\frac{a}{2} \sum_{n=1}^{N}\left|\eta_{i n}-\bar{\eta}_{i}\right|\right\}$

then

$V=\frac{a}{2} \sum_{i}^{I} \sum_{j=1}^{J}\left|\eta_{i}\right|+\frac{a}{2} \sum_{i}^{I} \sum_{n=1}^{N}\left|\eta_{i n}-\bar{\eta}_{i}\right|$

\section{NOTES}


NOTES 